\title{
Virtual Australia Developing an enabling platform to improve opportunities in the spatial information industry
}

The role that the development of Spatial Data Infrastructure initiatives is playing within the modern world is changing. Initially SDIs were implemented as a mechanism to facilitate access and sharing of spatial data hosted in distributed GISs. Users however now require precise spatial information in real time about real world objects and the ability to develop and implement crossjurisdictional and inter-agency solutions to priorities such as emergency management, natural resource management, water rights and animal, pest and disease control. In order to achieve this, the concept of an SDI is moving to a new business paradigm, where SDI is emerging as a 'virtual jurisdiction' or 'virtual enterprise' to promote the partnership of spatial information organisations (public/private) to provide access to a wider scope of data and services, of size and complexity that is beyond their individual capacity. The development of such an SDI requires an enabling platform to support the chaining of services across participating organisations.

This paper outlines the outcomes of research on the development of such an enabling platform within the context of a Virtual Australia. This includes a review of the spatial information and SDI developments in selected Australian state (Victoria, Western Australia and New South Wales) and international (Europe, Canada and USA) jurisdictions which are helping to move the concept of an enabling platform forward, the improving opportunities for $\mathrm{SI}$ industry through the development of an enabling platform, concepts and principles to aid in facilitating a Virtual Australia and recommendations for the future.

\section{A. Rajabifard \\ A. Binns \\ I. Williamson}

Centre for Spatial Data Infrastructures and Land Administration

Department of Geomatics, The University of Melbourne, Victoria AUSTRALIA 3010

abbas.r@unimelb.edu.au

a.binns@unimelb.edu.au

ianpw@unimelb.edu.au

\section{INTRODUCTION}

The current focus within the spatial information industry worldwide, especially throughout government is on the ability to develop and implement cross-jurisdictional and inter-agency solutions to priorities such as emergency management, natural resource management, water rights and animal, pest and disease control. These have become national priorities for countries such as Australia and the development of tools and functions to enable effective solutions to these issues is a major area of business for the spatial information industry. Much of the technology needed to create solutions to respond to such emergency management and counter terrorism situations and in delivering the "triple bottom line" objectives of sustainable development already exists, however the difficulty in bringing it together across jurisdictions is a major issue.

Up until now, individual jurisdictions have started utilizing different platforms in attempting to create mechanisms for accessing and delivering spatial data in a coordinated fashion. This has been done through the use of hierarchies of information. For example within Australia, local, state and national governments utilize Spatial Data Infrastructures (SDI) to make their data and information available. This information can be utilized both by those within a jurisdictional level as well as those at a different jurisdictional level. The benefits of SDI in enabling this sharing of information have been documented, however an SDI does not necessarily break down the 
barriers between jurisdictions. Just because different information can be gained about Victoria for example from different jurisdictional levels, does not mean that the information will necessarily be compatible (it may not be of the same accuracy or have the same specifications, utilize the same symbology, etc). There is now a need to move beyond a simple understanding of SDI and create a common rail gauge to aid in implementing initiatives that solve cross-jurisdictional and national issues. In order to meet this need, there is a requirement for an enabling platform and mechanism for spatial information coordination such as Virtual Australia. This would be a main gateway to find, access and communicate spatially enabled data and information about Australia.

With this in mind, Project 3.1 of the Cooperative Research Centre for Spatial Information (CRC$\mathrm{SI})$ has undertaken research towards developing "Concepts and Principles of Virtual Australia". The project was undertaken through collaboration between researchers and practitioners from academia, government and private industry. The outcomes of the project aim to provide a foundation for identifying key indicators and recommendations to aid in implementing an enabling platform and to inform discussion and debate within the spatial information community on the development of a Virtual Australia. This paper outlines the research outcomes of this project, including a review of spatial information developments in selected jurisdictions, the improving opportunities for SI industry through a Virtual Jurisdiction, and recommendations for the future including technical and institutional principles to aid in facilitating an enabling platform for the creation of a Virtual Australia.

\section{SDI AND VIRTUAL JURISDICTIONS}

SDIs have become a crucial tool in facilitating how spatial data and spatial information systems are used. They allow the sharing of data, which enables users to save resources, time and effort when trying to acquire new datasets. Effective use of spatial information requires the optimisation of SDIs to support spatial information system design and applications, and subsequent business uses. The need to find optimal SDI models requires ongoing research that reflects current social, cultural and business systems, as the measured benefits of building SDIs have not been as forthcoming as projected.

An SDI is a dynamic, hierarchic and multi-disciplinary concept that includes, people, data, access networks, institutional policy, technical standards and human resource dimensions as suggested by Rajabifard and Williamson (2001) and illustrated in Figure 1. SDIs have become very important in determining the way in which spatial data are used throughout an organisation, a nation, different regions and the world.

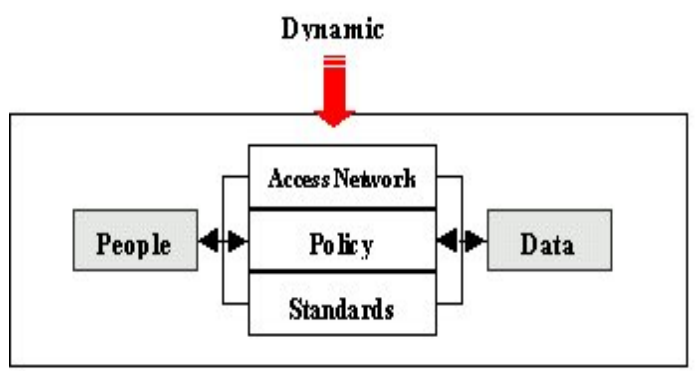

Figure 1: SDI Concept - Linking People

to Data
An SDI is developed for the purpose of supporting ready access to spatial information to support decision making at different scales for multiple purposes. It can be viewed as an infrastructure linking data users and providers on the basis of the common goal of data sharing. Such an entity can be enhanced so that it is possible to share in addition to data, business goals, strategies, processes, operations and value-added products - a virtual jurisdiction.

In this environment all types of organisations participating (incl. governments, industries, and academic) can gain access to a wider share of

the information market. This is done through organisations providing access to their own spatial data and services, and in return, becoming a contributor and hence gaining access to the next generation of different and complex services. In this setting, a virtual jurisdiction is a collaborative working environment, linking autonomous nodes that cooperate in order to achieve business goals and deliver services to their end users (Radwan et al., 2003). 
The benefits of such a virtual jurisdiction will be more than just the representation of feature based structures of the world; it will also include the administration and institutional aspects of such features, enabling both technical and institutional (eg. policies) aspects to be incorporated into decision-making. This is an aspect of research identified as more challenging than complex technical issues and is the focus of this paper (Rajabifard et al. 2005a).

The development of SDIs along with a review of other relevant spatial information initiatives relevant to the creation of a virtual jurisdiction for Australia were investigated within Project 3.1 of the CRC-SI. This review was undertaken within state based jurisdictions in order to find common initiatives and mechanisms which would help to create a common rail gauge for spatial information within Australia. Partners in the project came from the four states reviewed (Vic, NSW, WA, QId), as well as at a national jurisdictional level. An international level (Europe, USA, and Canada) review was also undertaken in order to investigate how initiatives within other countries have aided in breaking down barriers between jurisdictions within the spatial information sector.

\section{SPATIAL INFORMATION INITIATIVES}

Spatial information is a key underlying enabler in decision making and hence a major objective of the development of a virtual jurisdiction in Australia was to obtain an understanding of the spatial information needs and priorities of the states and territories, the Australian Government and industry. The understanding of state-federal relationships is particularly critical to the success of the project, as is articulating the framework of policies, protocols and standards for SDIs. Case studies were undertaken in the latter half of 2004 in various jurisdictions as mentioned above, with the outcomes helping to identify pathways (through development of initial concepts and principles) for the creation of a collaborative enabling platform that meets the vision of providing access to spatial applications and information such as modeling and visualisation tools.

\section{Case Study Overview - Australian National/State}

The case studies undertaken showed a variety of different approaches and progress being made within each jurisdiction in relation to the management, access and distribution of spatial information. The development of an SDI for each jurisdiction was the major driving force in the majority of spatial activity at both a federal and state level. National leadership through ANZLIC the Spatial Information Council, is attempting to lay the foundations for the creation of a nationwide SDI. So far however, the arrangements for SI sharing and access have been on a cooperative basis. Basic standards such as the ANZLIC metadata standards have been adopted but the depth and breadth of application varies across jurisdictions.

Australia has been a world leader in the development of SDI concepts and initiatives, however duplication of effort and expense is still occurring in some jurisdictions at various levels of administration, due in part to the federated system of government within Australia. There is also a general lack of interaction between the traditionally strong land and property information focus of spatial information with management of the natural resources, scientific information and socioeconomic information. This 'people relevant' spatial information is generally large-scale and has become the domain of State jurisdictions, which has seen the operational role of SDI development now being undertaken more at a sub-national government level (state and local government). This has seen an attempt to create systems in which spatial information from all sectors (land administration, natural resource management, etc) is available in an interoperable fashion.

State governments are beginning to implement such whole-of-government spatial information initiatives, including the creation of the Shared Land Information Platform (SLIP) in WA, the Victorian Spatial Council and Information Queensland. The major aim of these initiatives is to give cross-jurisdictional government agencies access to spatial information in a more efficient and effective manner. Instead of people having to deal with several different agencies to get information they need, one online system will provide access to key information controlled by 
various agencies. This is an attempt to move from 'silos' - where agencies tend to keep their expertise, data and knowledge within the agency - to a more accessible approach, reducing duplications and inefficiencies, improving service delivery and yielding strategic and commercial benefits for the Government.

Within this environment, the development of SDIs was found to be much more than simply the ability to utilise technology, but in developing policies, programs, logical and physical architecture and deliverables that remove the drivers for duplication of effort and begin to create a Virtual Australia. It was found that the development of SDIs within jurisdictions is hampered by insufficient evidence of their short and medium term benefits, leading to a resistance to change. There must be tangible benefits that can be quantified for development and implementation of SDIs is to be completed.

The technical basis for delivery of these whole-of-government on-line systems is through an interoperability architecture based on distributed, custodial data management and open standards. This is being implemented in the form of an enabling platform which provides uniform and consistent managed access to distributed web services operated by authoritative custodians (Starling et al. 2004). The aim of this architecture is to allow initiatives to grow in an open environment that gives agencies the ability to operate in an integrated manner. This type of architecture was also seen to be the most effective method of creating a national initiative through the creation of Virtual Australia. The spatial/textual infrastructure being developed by the Spatial Interoperability Demonstrator Project (SIDP) is based on the ASDI and has been developed in consultation with and evolved from collaboration with State based counterparts such as Western Australia and Queensland.

It was also noted throughout the case studies that the current initiatives being developed by governments do not fully take into account the needs of the private sector. This was especially relevant in the Queensland case study, with the Department of Natural Resources and Mines (DNRM) discussing the possibility of conducting research into the ability to create industry access to the majority of spatial information held by government agencies and departments (Rajabifard et al. 2005b). Giving the private sector access to the huge data resources of the State government would grow the industry exponentially through the creation of further products and tools.

Although Australia is a federation of states, it is cooperative federalism which aims to foster cooperation between jurisdictions and jurisdictional levels. States need to look at the progress being made and learn from other state based initiatives. All of the case study states claimed in some form to be developing an initiative which they perceived as best practice, or leading the other states in development. Each of these best practice initiatives needs to be developed across jurisdictions, reducing duplication of effort and creating a Virtual Australia at the same time.

Some of the issues and observations from the case studies which are relevant to the progression of research within the SDI sector and the creation of an enabling platform such as Virtual Australia include:

- SDI moving from 'data access' focus to a 'service/business delivery' focus - development needs to be driven by business needs.

- There is an inability to access data, particularly government data, and this is further compounded by the wide variety of systems and formats that the data is maintained.

- If effective policies are not in place within the sphere of an SDI to deal effectively with costs involved in data creation and distribution, then the ability of the industry as a whole to grow and develop at a fast pace is hindered.

- Technology was seen to be available to create and implement SDIs and a Virtual Australia, but cultural and institutional issues especially hindered associated implementation.

- Private/Public cooperation needed to build an SDI

o Private sector involvement enables SDI to be built to meet business needs.

o More discussion needed on the role that private sector can play in building SDIs. 
- Full-cost recovery policy for data inhibits rather than grows the spatial information industry in general:

o Limits use of data and hence limits the ability of the SI industry as a whole to grow and develop at a fast pace.

o WA and NSW have previously had 'full-cost recovery' policies and 'cost of extraction' policies. Both states found that 'cost of extraction' benefited the state as a whole much more than 'full-cost recovery'.

- Lack of spatial awareness and education - existing work practices do not include a strong culture of using maps and spatial information.

- Lack of cross-jurisdictional relationships.

- Implied control and privacy concerns over spatial information by various agencies limiting availability and access.

Collectively each state has been seen to be developing initiatives which would help to form a "Virtual Australia". There is a need to integrate these existing federal, state and local spatial data initiatives and policies for access and delivery of data/information. This will enhance the capability of government in addressing emergency management, counter terrorism and natural resource management initiatives in a cross-jurisdictional, national manner. It will also allow the private sector and the general community to engage in systems based, integrated and holistic decision making about the future of Australia, as information and tools will be available that cross, rather than are limited within, jurisdictional boundaries.

\section{Spatial Data Initiatives-International Perspective}

\section{Europe}

The development of the European Union over the past decade has brought together economic, social and political facets of European countries governance, creating the need for decision making across all jurisdictional levels within Europe. This has seen the need for harmonisation of spatial information delivery, with Europe making a strong and decisive effort in relation to building a European jurisdictional SDI, with several bodies formed and projects undertaken. The European Umbrella Organisation for Geographic Information (EUROGI) together with Open GIS Consortium Europe and the Joint Research Centre of the European Commission undertook a research project - GINIE: Geographic Information Network in Europe - "to develop a deeper understanding of the key issues and actors affecting the wider use of GI spatial information in Europe, and articulate a strategy to promote wider use that is consistent with major policy and technological developments at the European and international level" (GINIE 2004).

The strategic and policy implications of the results of the GINIE project found that like any other form of infrastructure (e.g. transport), for an SDI to work effectively it is necessary that:

- It operates at all levels: local, regional, national, European, global;

- It is well connected with other related infrastructures such as those of e-government, and public administration in general, research, and the private sector;

- It is regularly maintained;

- There are clear lines of responsibility for its development, operation, maintenance and regulation.

The results of the research also found that there was still major obstacles to spatial information development, including:

- Gaps in spatial data - Spatial data sets not compatible

- Lacking documentation - description of available spatial data is often incomplete

- Incompatible geographic information initiatives - the infrastructures to find, access and use spatial data often function in isolation only 
- Barriers to sharing and re-use - cultural, institutional, financial and legal barriers prevent or delay the use of existing spatial data

- Lack of coordination and leadership

- Isolation - GI communities isolated from e-government developments

- Gross underestimation of the cultural and organisational issues that influence the speed with which progress can be made

- Insufficient evidence of short and medium term benefits of SDIs leading to resistance to change

Evidence gathered throughout the GINIE project indicates that there is a need to focus less on data, and more strongly on other key components of SDIs, namely policy, coordination, and people.

Some of the issues identified within the GINIE project are also occurring within the development of Australia's SDI, especially in relation to the underestimation of the cultural and organisational issues that influence the speed with which progress can be made. As part of the results of the case studies undertaken within Australia, technologies for developing spatial infrastructures are currently being implemented within agencies and states and have been demonstrated through the Spatial Interoperability Demonstrator Project (Starling el al. 2004). The ability to actually implement this infrastructure across a range of agencies and stakeholders however can only occur effectively once institutional, cultural and organisational issues have been dealt with.

Whilst the GINIE project was being undertaken, there was also the development of the Infrastructure for Spatial Information in Europe (INSPIRE) initiative by the European Commission. The aim of INSPIRE was to "make available relevant, harmonised and quality geographic information to support formulation, implementation, monitoring and evaluation of Community policies with a territorial dimension or impact" (GINIE 2004). The initiative intends to trigger the creation of a European spatial information infrastructure that delivers to the users integrated spatial information services.

A proposal for a Directive of the European parliament and of the Council of Ministers establishing INSPIRE was put forward in Brussels on the $23^{\text {rd }}$ of July 2004. The proposed Directive creates a legal framework for the establishment and operation of an Infrastructure for Spatial Information in Europe, for the purpose of formulating, implementing, monitoring and evaluating community policies at all levels and providing public information (Masser 2005). The directive is important as research has found that "few countries have developed a framework for establishing a national infrastructure for spatial information that addresses operational, organisational and legal issues" (Commission of the European Communities 2004), This is also often the case within Australia, with infrastructure developments being implemented without addressing organisational and legal issues, ending in the infrastructure not being readily useable and available to all stakeholders. The frameworks adopted are also often specific to regions or specific industry sectors (such as land administration or environmental management). This is an area which the development of a Virtual Australia aims to address.

The framework being developed within Europe would be to a large extent funded by the public sector and it is estimated that it would cost each country on average 3.6-5.4 million Euro per annum, representing only one percent of the total expenditure on spatial information. An extended impact assessment was carried out for INSPIRE, with benefits from this investment found to include environmental gains, wider social benefits and gains by the private sector. As yet, the environmental benefits are the only ones quantified with the average annual benefit per country amounting to 27-42 million Euro. The conclusion drawn was that the benefits outweigh the investment requirements by a considerable amount (INSPIRE 2005).

The directive has since been adopted by the Commission, the first step in a co-decision procedure that should lead to the formal adoption of the INSPIRE Directive, which then has to be implemented in every EU Member State (INSPIRE 2005). 


\section{USA}

In the USA, discussion on a National SDI initiative started in late 1980 primarily in the academic community. The Federal Geographic Data Committee (FGDC) was formed in 1990 by the Office of Management and Budget to help coordinate federal geospatial data activities (Tosta 1999) and further spatial information activity progressed rapidly after the Executive Order from the President's Office was issued in 1994 (Executive Order 1994).

This Executive Order established a legal basis for more aggressive federal efforts to advance the NSDI toward full implementation in partnership with state, local and tribal governments, academia and the private sector (Reichardt and Moeller 2000). Currently there are three major areas of development of a National SDI (NSDI) for the USA. These include the Federal Geographic Data Committee (FGDC), Geospatial One-Stop (GOS) and The National Map. The relationship between the three is shown in Figure 2.

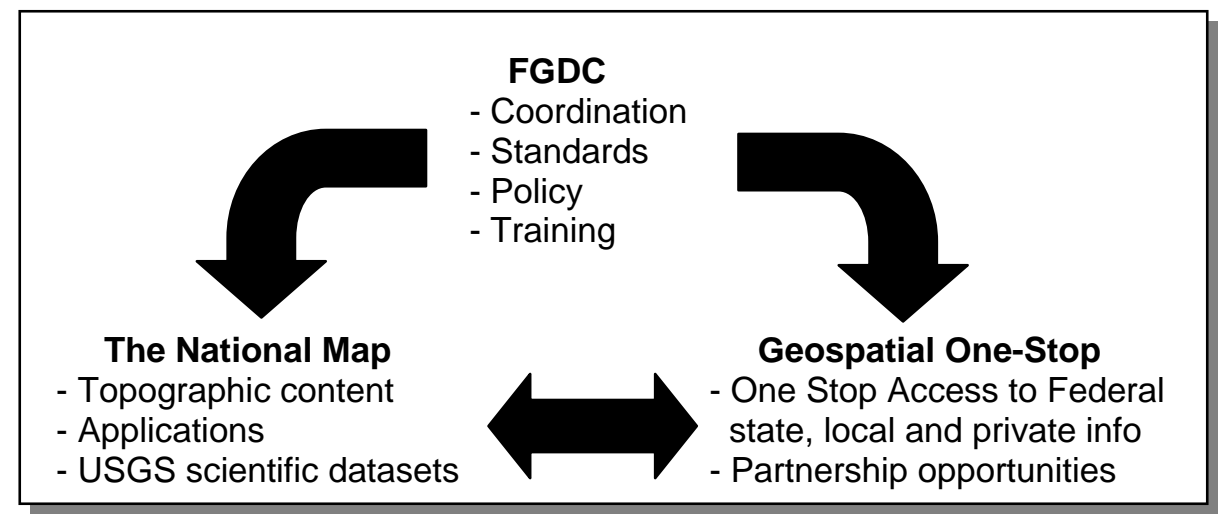

Figure 2: Relationship between FGDC, The National Map and Geospatial One-Stop

(Ryan et al. 2004)

The FGDC has the ongoing responsibility for coordinating spatial activities. It focuses primarily on spatial data standards, policies, clearinghouse technology, education and outreach. This committee works towards the implementation of what the FGDC sees as the six basic building blocks of the NSDI: metadata; clearinghouse; standards; framework; geospatial data; and partnerships which all contribute to building a distributed network of producers and users that facilitate data sharing. The FGDC is not dissimilar to Australia's current spatial information council, ANZLIC, which promotes and contributes to the policies, access network, data, people and standards that make up the Australian Spatial Data Infrastructure (ASDI).

The GOS on the other hand, is one of 24 e-Government priorities that are aiming to make it easier, faster and less expensive for all levels of government and citizens to access spatial information. From a policy perspective, it adds three unique benefits to the implementation of the NSDI including:

- Raising the visibility of the strategic value of geographic information

- Increasing federal accountability for geospatial data stewardship, and

- Establishing a collaborative model for an intergovernmental initiative

The establishment of the GOS also gives the implementation of an NSDI a sense of urgency and importance, not seen within countries such as Australia, as the GOS implements the basic elements of the NSDI by providing an Internet portal to facilitate data sharing and encourage decision support across all jurisdictional levels of the country, an initiative that is important in the creation of any Virtual Jurisdiction. 
The National Map initiative provides the integrated base geographic data in partnership with content producers at all levels. The initiative provides sufficient consistency to meet applications needs across federal, state and regional jurisdictional levels. Users are able to utilise spatial information for base mapping operations, including orthoimagery, elevation, hydrography, boundaries, land cover, geographic names, transportation and structures (buildings and selected critical infrastructure).

Due to Australia's federated system of government, the datasets discussed within the USA's National Map initiative are the domain of state governments in Australia. This has slowed the creation of useable, scalable national datasets. The Public Sector Mapping Agency (PSMA) is currently the organisation within Australia that amalgamates state datasets to form national ones and acts as a clearinghouse for Australia wide datasets. This is an important aspect of creating a national base from which other spatial datasets can build on. PSMA however is limited in its ability to form national datasets by the different standards, accuracies and issues of interoperability between the various states in relation to datasets such as hydrography, transport and structures.

\section{Cross Agency Initiatives}

In early 2004 the FGDC, GOS and The National Map were seen to share a common problem, in that the spatial information community, especially outside of the federal network, was confused about the interrelationships among the three programs and concerned about the perceived duplication of effort among their activities. A summit of the senior leaders of these organisations was held to agree on and realign the three programs and communicate the roles and responsibilities of each. The specific roles of the programs, as described above were found to be sound, however the summit also identified cross-agency initiatives which should be undertaken to consolidate the creation of the NSDI and reduce perceived duplication of effort.

One of the most important agreements made between the three agencies which is also relevant to Australian SDI development is the fact that GOS will rely on the National Map as the underlying provider of base content for all other GOS supplied datasets. This gives the USA a base layer of fundamental data from which all other jurisdictional levels are able to work from. This type of initiative is also important in the creation of a Virtual Australia combining all jurisdictional levels. There was also pledge by FGDC to revitalise its efforts in leading a broad range of standards activities as both the GOS and National Map are highly dependent on the broad adoption of spatial data and information processing standards. In return, the National Map has pledged to support the standards efforts of the FGDC (FGDC 2004). This is an important step, as it gives the FGDC the mandate to create standards that it knows will actually be implemented and utilised in creating an NSDI. Within Australia, standards created by agencies such as ANZLIC and OGC are often implemented on an ad hoc basis by various players within the spatial information sector. The creation of Virtual Australia could only occur if it was able to gain an agreement on the implementation of national standards and processes from all jurisdictions in Australia.

Another lesson learnt from the issues facing the three agencies in the USA is that the building of Virtual Australia must be undertaken through the utilisation of technologies and outcomes of state and national based initiatives which are currently being built on the back of distributed SDI enabling platforms. It is important not to re-invent the wheel.

\section{Canada}

Work on the Canadian Geospatial Data Infrastructure (CGDI) began in the mid nineties with various government and industry bodies combining their efforts to create a CGDI. To realise the CGDI the Canadian Government set up and funded GeoConnections, an agency which brings together all levels of government, the private sector and academia. Five key policy areas have been identified that would enable GeoConnections to create a CGDI and include; Accessing Data, Establishing Framework Data, Geospatial Standards, Creating Partnerships, and Developing Supportive Policy. 
GeoConnections has had \$60million (Canadian) in funding over six years from 1998 undertaking different projects ranging from activities of coordination and communication to policy and research. GeoConnections received a further $\$ 60$ million in funding in 2004 in order to continue its current work in the development of the CGDI. The implementation of the CGDI is widely regarded as a leader in creating opportunities for all facets of industry (government, private sector and academia) by other countries developing SDIs.

The development of Service New Brunswick (SNB) is also very relevant to the concept of a 'Virtual Australia'. SNB is the Province of New Brunswick's gateway for the electronic delivery of a wide range of basic government services. Its mission is "to improve the accessibility of government services and to be stewards for authoritative public information" and provides "simple, fast and secure access to products, services and information" (SNB 2005). It is interesting to note that the Vision for SNB is "government services on time, every time, everywhere" (SNB 2004). SNB has four main lines of business delivered through a web portal including Property Assessment (all land, buildings and improvements), Registries (real and personal property registries), Government Service Delivery (more than 197 government services) and Geographic Information Infrastructure.

There is a geographic data and maps section which gives access to freely available geographic information of New Brunswick, made possible through contributions provided by GeoConnections. SNB generated revenue of nearly $\$ 48.9$ million (Canadian) in the year 20032004 against approx 47-48 million in expenses (SNB 2004). The development of SNB shows how the generation of a spatial information infrastructure (SNB maintain the infrastructure for New Brunswick) can aid in creating value added services and act as a one-stop shop to products, services and information from many agencies.

\section{VIRTUAL AUSTRALIA - IMPROVING OPPORTUNITIES FOR SI INDUSTRY}

The investigation of current spatial information initiatives undertaken within several jurisdictions provides insight into the facets of research needed to create a Virtual Australia. The development of a Virtual Australia is a key objective of the CRC-SI's mission to unite research and commercial innovation in spatial information. The ability to move the concept of Virtual Australia forward within the spatial information industry as a whole however has been hampered by the fact that the exact meaning and concept of Virtual Australia has not been defined. This hinders the ability of the CRC-SI to meet its vision and mission through the development of an effective research program, and also limits the CRC-SI's ability to engage stakeholders to contribute to the facilitation of Virtual Australia.

The adjective "virtual" is used in various ways to denote things, activates and organisations that are realised or carried out chiefly in an electronic medium. For example virtual conversations are carried out over computer networks and virtual communities are actual social groups that assemble around the use of email, web pages and other networked sources. The term jurisdiction is the extent of authority or control or territorial range of authority or control over a specific area. Putting these two words together and the term virtual jurisdiction means an entity (such as a government) representing a defined territory (such as the State of Victoria) operating in an electronic medium, principally the internet.

The concept of an SDI is created for the purposes of supporting ready access to spatial information. The focus now however has gone beyond simply accessing spatial information. The focus within the spatial information industry throughout government and the private sector and community is now on service/business delivery and the need to create a platform from which tools and functions associated with services/business link off. Current SDI models have not met user needs as expected, currently only providing a limited ability to access spatial data. Hence the concept of an SDI needs to be progressed so that it allows more than just the ability to access spatial information. It needs to become an entity which is enhanced so that it is possible to share in addition to data, business goals, strategies, processes, operations and value-added products a virtual jurisdiction. This concept then needs to be related across all jurisdictions within Australia 
if it is to meet the vision for access to spatial information applications anytime, anywhere - a Virtual Australia.

The Project research team consulted with participating organisations to discover what the term and expectations of Virtual Australia are to them. The concept of an SDI as the enabling technology to be utilised in the development of Virtual Australia was common across the definitions and expectations of Virtual Australia. There was however also general uncertainty in the concept of Virtual Australia, raising the importance of the need for the concept to be defined in greater depth. This will enable all partners and projects related to the development of a Virtual Australia to move in the same direction.

Stakeholders were also asked if current spatial information arrangements meet user needs with Table 1 showing the four responses to the question. Generally current arrangements for accessing and sharing spatial information do not meet user needs. The exception was from Western Australia, which cites institutional arrangements including the creation of WALIS and various custodianship, pricing and metadata policies as being the major catalyst for the creation of a culture of information sharing.

\begin{tabular}{|c|c|c|c|}
\hline \multicolumn{4}{|c|}{ Do current Spatial Information arrangements meet user needs? } \\
\hline $\begin{array}{l}\text { Victorian Government } \\
\text { Stakeholder Response }\end{array}$ & $\begin{array}{l}\text { WA Government } \\
\text { Stakeholder Response }\end{array}$ & $\begin{array}{l}\text { Victorian Government } \\
\text { Stakeholder Response }\end{array}$ & $\begin{array}{c}\text { Commonwealth } \\
\text { Government } \\
\text { Stakeholder Response }\end{array}$ \\
\hline $\begin{array}{l}\text { Not at all. Some data is easy } \\
\text { to access. Vicmap, CGDL, } \\
\text { some government } \\
\text { departments, but most data } \\
\text { is very difficult to track down } \\
\text { as they are not proper spatial } \\
\text { datasets, therefore not listed } \\
\text { in the VSDD, etc. Even when } \\
\text { they are, a lot of } \\
\text { organisations probably don't } \\
\text { know about the VSDD and } \\
\text { spatial data policy. }\end{array}$ & $\begin{array}{l}\text { Within Western Australia the } \\
\text { WALIS framework has existed } \\
\text { since the early 1980's for, } \\
\text { improving access to, and the } \\
\text { sharing of information } \\
\text { amongst member agencies. } \\
\text { Institutional arrangements } \\
\text { including the WALIS } \\
\text { custodianship policy, pricing } \\
\text { policy and metadata policy } \\
\text { have all contributed to a } \\
\text { successful culture of } \\
\text { information sharing. }\end{array}$ & $\begin{array}{l}\text { Only meeting very basic } \\
\text { requirements through ad } \\
\text { hoc and limited } \\
\text { accessing and sharing } \\
\text { arrangements. }\end{array}$ & $\begin{array}{l}\text { Current spatial } \\
\text { information arrangements } \\
\text { do not meet user needs. }\end{array}$ \\
\hline
\end{tabular}

Table 1 - Responses to question on spatial information arrangements

The concept and delivery of Virtual Australia must enable users from all industries and information sectors to access both spatial information (generally held by governments) and applications which utilise spatial information (developed by the CRC-SI, the private sector and governments). The following is a definition of Virtual Australia, taking into account participant feedback:

Virtual Australia is an enabling platform that supports a knowledge base to provide a major point of discovery and communication to complete, correct and current information about the natural and built environment and related affordable spatial information applications, in a useable and readily available manner at anytime and in anyplace.

With this in mind, the aim of Virtual Australia is to create an enabling platform to support government and business activities and services at both a small and large scale. As shown in Figure 3, Virtual Australia is a vehicle from which both textual and spatial data are utilized to form a range of supported functions for those within the industry as well as non-spatial and nontechnical user groups. Each state jurisdiction has a range of initiatives and functions being both used and created often in isolation from one another. The creation of Virtual Australia will help to 
modularize the development of SDI - creating services and functions that can be utilized at further levels up the information chain, including across jurisdictions (Rajabifard et al. 2005a).

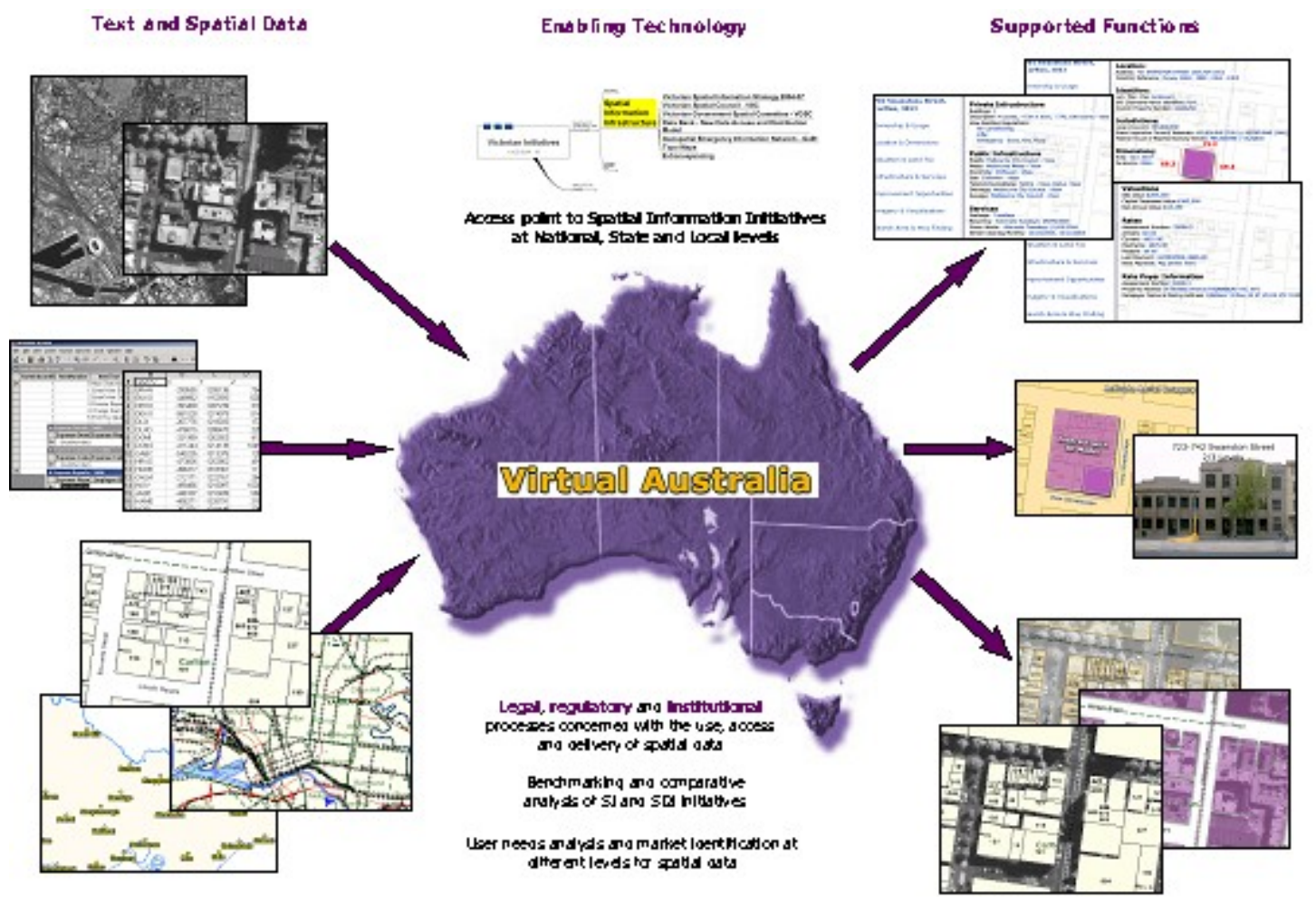

Figure 3: Concept of Virtual Australia

The creation of a Virtual Australia would lower barriers to access and use of spatial data, to both government and the wider community, and particularly to the spatial information industry. If barriers are minimised, then entities would be able to pursue their core business objectives with greater efficiency and effectiveness. In particular, industry would be able to reduce their costs, which would encourage investment in capacity for generating and delivering a wider range of spatial information products and services to a wider market, both in Australia and internationally.

The development of such a virtual system requires a set of concepts and principles to enable the design of an integration platform that facilitates interoperability and inter-working of functional entities within a heterogeneous environment. The spatial data communities within any jurisdiction can benefit from the various models and tools that have been developed in other jurisdictions for integrated modeling, as well as the work of Open GIS Consortium (OGC) to develop standard, interoperable access interfaces, to facilitate access to GIS services over the Internet (Web Services, Internet GIS).

\section{DEVELOPING VIRTUAL JURISDICTION-CONCEPTS AND PRINCIPLES}

As a result of the overview of SDI and SI initiatives within different jurisdictions, the development of a preliminary set of concepts and principles that will aid in facilitating the formation and development of an enabling platform have been identified. These have been developed to inform discussion and debate on how to go about developing an enabling platform for the delivery of a Virtual Australia.

\section{Concepts}

Concepts relating to a Virtual Jurisdiction which can be used in developing an enabling platform are needed in order to guide its development and should enable the creation of functions that users and stakeholders need to carry out their business needs. Based on the definition of Virtual 
Australia, the following is a preliminary set of concepts (Table 2) that contribute to the overall Virtual Australia vision, defining in more detail what the creation of a framework for Virtual Australia will achieve.

\section{CONCEPTS}

1. Virtual Australia should provide complete data about all jurisdictions in Australia including information describing the nations built and natural environments

3. Virtual Australia should enable the government, private sector and the general community to engage in systems based, integrated and holistic decision making about the future of Australia, based on:

a) an enabling environment to support government and business activities

b) the inclusion of intuitive information sources and tools using spatial information for non-spatial, nontechnical users

5. Virtual Australia architecture should allow stakeholders to expose their content and services to the network for others to build on, but the architecture must enable stakeholders to continue to manage business solutions and control their internal technological environments

7. Virtual Australia should optimise current SDIs to support spatial information system design and applications and subsequent business uses
2. Virtual Australia should allow all types of data to be analysed at any one time, subject to appropriate security, privacy and commercial considerations

4. Virtual Australia should focus on proven technology which is currently utilised by stakeholders in the development of their SDIs as:

a) the costs associated with building a completely new platform will be high; and

b) if the platform is not compatible with current spatial information initiatives, it will not be utilised

6. Virtual Australia will negate the need to visit individual agencies or organisations to undertake tasks. Virtual Australia should be the community gateway to spatial data and spatial data services for all jurisdictions in Australia

8. The creation of Virtual Australia will help to modularize the development of SDI - creating services and functions that can be utilized at further levels up the information chain, including across jurisdictions

Table 2: Virtual Australia Concepts

\section{Principles}

In order to support the concepts of an enabling platform in Australia, the following principles (Table 3) have been developed to aid in the creation of a Virtual Australia framework. These are by no means definitive, but are a starting point for debate and further research into the development of Virtual Australia. These have been divided into institutional, technical and data/information sections in order to gauge the impact of each principle to its relative area of research. 


\begin{tabular}{|l|l|l|}
\hline \multicolumn{1}{|c|}{ Institutional } & \multicolumn{1}{|c|}{ PRINCIPLES } \\
\hline $\begin{array}{l}\text { Virtual Australia must be built on a } \\
\text { network of state systems (currently } \\
\text { based on SDIs), the installation and } \\
\text { operation of which shall be the } \\
\text { responsibility of each state. This will } \\
\text { facilitate the integration of existing } \\
\text { federal, state and local spatial } \\
\text { information initiatives for access, } \\
\text { delivery and usage of data and } \\
\text { information }\end{array}$ & $\begin{array}{l}\text { New data quality procedures } \\
\text { (including visualisation of data } \\
\text { quality) must be introduced in } \\
\text { order to ensure fitness for purpose } \\
\text { and use - the creation of } \\
\text { metadata (or lack of) by agencies } \\
\text { has not produced the desired } \\
\text { results within current spatial } \\
\text { information practice }\end{array}$ & $\begin{array}{l}\text { Technical } \\
\text { Dirtual Australia shall be } \\
\text { provided to harmonised data } \\
\text { specifications and to } \\
\text { common, agreed standards, } \\
\text { based on distributed } \\
\text { custodial management of } \\
\text { services and content }\end{array}$ \\
\hline $\begin{array}{l}\text { Appropriate coordination } \\
\text { mechanisms and common rules } \\
\text { between stakeholders involved in the } \\
\text { establishment of Virtual Australia } \\
\text { need to be created - partnerships } \\
\text { are the key to creating a Virtual } \\
\text { Australia }\end{array}$ & $\begin{array}{l}\text { Framework data, the scope and } \\
\text { composition of which shall be } \\
\text { specified by ANZLIC in } \\
\text { consultation with stakeholders, will } \\
\text { provide the framework that } \\
\text { underpins other data within Virtual } \\
\text { Australia }\end{array}$ & $\begin{array}{l}\text { The technical architecture of } \\
\text { Virtual Australia must be } \\
\text { designed to meet the needs } \\
\text { of all producers, users and } \\
\text { other stakeholders, through } \\
\text { a set of specific applications } \\
\text { and functions }\end{array}$ \\
\hline $\begin{array}{l}\text { Harmonized licensing frameworks } \\
\text { will form part of Virtual Australia to } \\
\text { facilitate and optimise the sharing, } \\
\text { trading and extensive use of data } \\
\text { and information within Virtual } \\
\text { Australia }\end{array}$ & $\begin{array}{l}\text { Maintenance of data within Virtual } \\
\text { Australia is to be completed at } \\
\text { regular intervals as agreed by all } \\
\text { participating stakeholders - this is } \\
\text { especially relevant to framework } \\
\text { data }\end{array}$ & $\begin{array}{l}\text { Virtual Australia must have } \\
\text { common access and } \\
\text { delivery protocols for all } \\
\text { information through the } \\
\text { distributed network }\end{array}$ \\
\hline
\end{tabular}

Table 3: Virtual Australia Principles

\section{CONCLUSIONS AND FUTURE DIRECTIONS}

The spatial information community is attempting to meet the cross-jurisdictional needs of communities of practice such as natural resource and water management and counter terrorism through the development of innovative tools and applications. For this to occur effectively however there is the need to provide access mechanisms for the delivery of spatial data in a coordinated fashion across all levels and jurisdictions.

This paper has discussed research undertaken with the aim to contribute to the vision and strategic development of an enabling platform, drawing on data and information from all jurisdictional levels in Australia to facilitate Virtual Australia. The project reviewed and assessed existing spatial information initiatives and activities within different jurisdictions (state, national and international) outlining an overview of current practice with the aim to inform debate, and to contribute to the future concept of a Virtual Australia, which would be a gateway to discover and communicate spatially enabled information. As a result, a preliminary set of concepts and principles have been developed (Full list available in CRC-SI Project 3.1 Report - Concepts and Principles of Virtual Australia, available at www.crcsi.com.au). These aim to help move the vision of Virtual Australia towards the creation of a strategy and roadmap for the realization of Virtual Australia through building institutional capacity amongst all sectors of the spatial information community.

This paper has attempted to begin the process of defining the concept of an enabling platform by examining and contributing to the concept of a Virtual Australia. The ability to unite research and commercialisation within the spatial information sector to aid in the development of Virtual Australia is a major aim of the CRC-SI. Until now however, the concept of Virtual Australia has 
not been effectively defined. It is important to note that the research project has not attempted to create a definitive definition and set of principles for a Virtual Australia. The project, through a scan of spatial information and SDI related activities in selected jurisdictions across Australia and through a limited international scan, has attempted to inform discussion and debate, outlining further research areas that will aid in realising a Virtual Australia.

The study of international initiatives shows the importance to which the creation of an enabling platform has been given within the major economic jurisdictions of the world (Europe, Canada, USA). All of the international countries investigated are developing SDIs at national, state and local levels through a standards based distributed network utilising web services (such as OGC developed WMS, WFS which expose functionality and data through the web) and other interoperable initiatives. This is in-line with current state based practices in Australia.

It was interesting to note however, the difference in SDI implementation between Europe and all of the other jurisdictions (including Australia). Europe was the only jurisdiction to be using a legislative approach in attempting to create a European SDI. This process is not seen in many jurisdictions investigated.

The inclusion of the private sector in the development of spatial infrastructure is an important conclusion drawn from international practice especially within Canada. Service New Brunswick is a functional operating SDI which delivers a range of products, services and functions from across agencies through one portal. This development has come about through effective institutional practices and the creation of linkages between government agencies, the National SDI initiative and the private sector.

There is general consensus that current arrangements for accessing and sharing spatial information do not meet all user needs. Each case study state has been seen to be developing initiatives to address this, which together would aid in the development of a Virtual Australia. The achievement of Virtual Australia is largely dependent on collaboration between all parties and importantly having effective SDI and spatial information system designs to support efficient access, retrieval and delivery of spatial information to locations where it is needed from locations where it is stored. In order for this to occur, there is a need for the development of appropriate SDI performance indicators and benchmarking methodologies of the underlying Australian SDI initiatives.

\section{Recommendations}

The following is a list of recommendations stemming from research work undertaken. These recommendations have been developed to aid both the CRC-SI and spatial information community as a whole in achieving its goal to unite research and commercial innovation to aid in the development of a Virtual Australia:

- It will be important that the concept of Virtual Australia is based upon framework policies, protocols and standards for SDIs at all jurisdictional levels and moves forward through adoption of the latest technologies as exhibited in current systems.

- There is a need to foster and develop relationships at the technical development and implementation level within Government. There is currently good communication between the various jurisdictions at the higher level of government, but there is a lack of crossjurisdictional relationships at the technical level, hindering the effective implementation of cross-jurisdictional spatial information initiatives.

- From the work undertaken within the Project, there was seen to be four major dimensions to creating a Virtual Australia:

- data and its sources

- $\quad$ the technological infrastructure for using it

- the various policy settings of public agencies that influence it

- $\quad$ the governance framework for running it 
If Virtual Australia is to be developed and implemented, then work within all four of these areas needs to be undertaken.

- An investigation into the business needs of stakeholders and the broader community within the spatial information sector should be undertaken. The ability to create a Virtual Australia must be dependent on business needs - there needs to be significant business drivers for an infrastructure to be built.

- Research is needed into the way that data (both spatial and non-spatial) is to be stored, used and accessed in the future. The use of Grid-computing, Data Hubs and various other technologies that are beginning to have an increasing effect on creating global information repositories need to be investigated, in order to conclude their relevance and applicability to the huge amount of spatial data that both governments and other private stakeholders hold.

- The use of open standards and an interoperable enabling platform will allow initiatives to be brought together within Virtual Australia, reducing duplication of effort. The case for interoperability however has not been sufficiently made in both private and public contexts. This must be strengthened.

- There is a need to develop institutional practices to make existing and future technology more effective. It is the operational, organizational and legal issues that will enable the infrastructure to be readily useable and available to all stakeholders and must be researched within the context of Virtual Australia.

- Commercial, privacy and intellectual property issues with regards to the sharing of data are all common concerns of government and data providers and continue to be a barrier to creating more efficient access to all of the spatial information relating the Australia. Jurisdictions need to develop effective communication channels to discuss and find solutions to these issues within the context of information access and sharing.

Further development of Information and Communications Technology, as well as developments in the area of Computing and Data Base Management may begin to provide some other ways of going about the creation of a Virtual Australia. Design strategies for Virtual Australia need to link the old - state based SDI infrastructure development, with the new - developed functions and principles identified within research and new developments in technology, in an interoperable way. The research being undertaken as part of this project aims to begin the process of overcoming the inherent, locked-in effects that current systems have created over time, providing an enabling environment in which spatial based applications and user communities can grow.

\section{ACKNOWLEDGEMENTS}

The authors would like to acknowledge the support of the Cooperative Research Centre for Spatial Information, the University of Melbourne, and the members of the Centre for SDIs and Land Administration at the Department of Geomatics, the University of Melbourne, in the preparation of this paper and the associated research. The Authors would also like to thank Project 3.1 partners including the Department of Lands NSW, Department of Sustainability and Environment Vic, Department of Agriculture and Department of Land Information WA, Department of Natural Resources and Mines QId, Geoscience Australia, and Integraph. However, the views expressed in the paper are those of the authors and do not necessarily reflect the views of these groups.

\section{REFERENCES}

Commission of the European Communities (2004), Proposal for a Directive of the European Parliament and of the Council Establishing an Infrastructure for Spatial Information in the Community (INSPIRE), SEC(2004) 980, Brussels, http://inspire.jrc.it/home.html, accessed 25 January 2005. 
Executive Order (1994), Coordinating geographic data acquisition and access: the National Spatial Data Infrastructure, Executive Order of the White House, Office of the Press Secretary, USA.

Federal Geographic Data Committee (FGDC) (2004), NSDI Future directions initiative: towards a national geospatial strategy and implementation plan, Reston VA: Federal Geographic Data Committee, http://www.fgdc.gov (accessed 19 March 2005).

GINIE (2004), Geographic Information Network in Europe (GINIE) Final Report, Report D 1.5.1, January 2004.

INSPIRE (2005), INSPIRE Home Page, INSPIRE Step-wise implementation approach, http://inspire.jrc.it/home.html, accessed 25 January 2005.

Masser, I. (2005), GIS worlds: creating spatial data infrastructures, Redlands CA ESRI Press.

Radwan, M., Alvarez, A., Onchaga, R. And Morales, J. (2003), Designing an Integrated Enterprise Model to support Partnerships in the Geo-Information Industry, MapAsia, 2003.

Rajabifard, A., Binns, A. and Williamson, I. (2005a), Development of a Virtual Australia Utilising an SDI Enabled Platform, Global Spatial Data Infrastructure 8 and FIG Working Week Conference, 14-18 April, Cairo Egypt.

Rajabifard, A., Binns, A. and Williamson, I. (2005b), Report on Current Spatial Data Initiatives around Australia - Potential and Limitations, Cooperative Research Centre for Spatial Information, http://www.crcsi.com.au, accessed 10 October 2005.

Rajabifard, A. and Williamson, I.P. (2001), Spatial Data Infrastructures: Concept, SDI Hierarchy and Future directions, Proceedings of GEOMATICS'80 Conference, 29 April-2 May 2001, Tehran, Iran.

Reichardt, M. E. and Moeller, J. (2000), SDI Challenges for a New Millennium- NSDI at a Crossroads: Lessons Learned and Next Steps. 4th Global Spatial Data Infrastructures Conferences, 13-15 March 2000, Cape Town, South Africa.

Ryan, B., DeMulder, M., DeLoatch, I., Garie, H. and Siderelis, K. (2004), A Clear Vision of the NSDI, Federal Geographic Data Committee Newsletter, 2004 Winter Edition.

Service New Brunswick (SNB) (2004), Annual Report 2003-2004, Service New Brunswick, http://www.snb.ca, accessed 14 February 2005.

Service New Brunswick (SNB) (2005), Service New Brunswick Home Page, http://www.snb.ca, accessed 14 February 2005.

Starling, R., Wilson, M. and Mason, R. (2004), Notional Architecture for a Geo-enabled Enterprise Portal Platform for the AusIndustry Spatial Interoperability Demonstration Project, Volume 1 - Summary, Version 1.0, August 17th 2004.

Tosta, N. (1999), NSDI was supposed to be a verb, Integrating Information Infrastructures with GI Technology, B. Gittings. UK, Taylor \& Francis. 1. 


\section{University Library}

\section{- M M I N E R VA A gateway to Melbourne's research publications}

Minerva Access is the Institutional Repository of The University of Melbourne

Author/s:

Rajabifard, A.;Binns, A.;Williamson, I. P.

Title:

Virtual Australia: developing an enabling platform to improve opportunities in the spatial information industry

Date:

2006

Citation:

Rajabifard, A., Binns, A., \& Williamson, I. P. (2006). Virtual Australia: developing an enabling platform to improve opportunities in the spatial information industry. Journal of Spatial Sciences, 51(1).

Publication Status:

Published

Persistent Link:

http://hdl.handle.net/11343/33582 